\title{
Cost-Effective And Environmental Friendly Distribution Transformer
}

\author{
Manish Kumar Srivastava
}

\begin{abstract}
The scope of this paper is to focus on cost effective design, reliable and environment friendly distribution transformer. The huge number of distribution transformer is required for electrification of any country so cost effective design is required. Oil immersed distribution transformer can be built with very low losses compared to dry- type transformers. Planning long tem responsibility to global environment this should be emphasized together with low fire risk, non-toxic biodegradable or recyclable materials. Envirotemp FR3 is a natural ester made from edible seed oils and is $99 \%$ biodegradable [1]. Use of the FR3 oil for transformer cooling, makes transformer reliable and environmental-friendly.
\end{abstract}

Index Terms - Flux density and current density, Distribution transformer, FR3 oil, Weight and size reduction

\section{INTRODUCTION}

Electricity is modern society's most convenient and useful form of energy. The increasing per capita consumption of electricity throughout the world reflects a growing living standard of people while demand has increased the need for a steady power supply with minimum power interruption, and fast fault restoration has also increased. The optimum utilization by society of this form of energy can be ensured by an effective distribution system. Transformer is important equipment and commonly use in transmissions and distributions system and they are responsible for the stable and reliable power system. The failure of one transformer may cause significant effect for electrical utilities failure causes large outage and economic losses.

The huge numbers of distribution transformers are required for electrification of any country [2]. It is estimated that number of distribution transformer installed in electrical distribution network is growing approximately $1.5 \%$ per annum [3]. Around $15 \%$ of investment in transmission system goes towards transformer [4]. To meet this requirement, large amount of money is required, therefore cost-effective distribution transformer is necessity.

This paper presents a cost effective design of distribution transformer as well as suggests using FR3 oil in place of mineral oil for reliable operation of transformer.

\section{CONCEPT OF RELIABILITY}

As country's energy demand continues to grow, the electric utility industry is increasingly looking to new, environment friendly and cost -effective methods to meet the nation's energy needs. Many utilities are committed to improving the safety and reliability of electrical transformers.
FR3 is an insulating fluid that offers many benefits including increased fire and environmental safety, and enhanced performance and longevity of the transformer envirotemp FR3 fluid is a fire resistant natural ester based dielectric coolant specifically formulated for use in distribution transformers where its unique environmental, fire safely, chemical and electrical properties and advantageous.

The following property of FR3 oil explains its advantages.

- $\quad$ Envirotemp FR3 fluid has an exceptionally high fire point of $360{ }^{\circ} \mathrm{C}$ and flash point of $330{ }^{\circ} \mathrm{C}$. It has the highest ignition resistance of less flammable fluids currently available [5].

- $\quad$ FR3 fluid is a low, one time investment that can pay for itself many times over by extending the life of the transformer, decreasing the maintenance costs [6].

- $\quad$ FR3 fluid extends the life of the insulating paper by 5 to 8 times- which directly extends the expected thermal life of a transformer [7].

According to the latest BEES report (4.0e), a 1000KVA rated transformer containing 500 gallons of envirotemp FR3 fluid lasting 30 years has an estimated carbon foot print of roughly $34,260 \mathrm{~g}$ co2e/unit, where as a transformer with same specifications containing mineral oil has a carbon foot print of 1, 899, 973gco2e/unit in other words, mineral oil produces 56 times more carbon emission than that of the FR3 transformer fluid [7].

World demand of petroleum is expected to increase over $40 \%$ by 2030 which will contribute to the depletion of our increasingly limited supplies of oil. As supplies are limited FR3 fluid provides a sustainable alterative to traditional mineral oil as its main ingredient is form a renewable resource [7].

- Today many companies across the country are taking advantage of this FR3 oil, despite the fact that it costs on average $\$ 15$ per gallon more to purchase cooper power claims that their new vegetable oil based transformers will outperform and over the long run cost less than transformers filled with the standard petroleum-based mineral oil [8].

- $\quad$ Soybean oil- based or vegetable-based transformer fluids promise to be better for the environment while boosting the local farming economy [8].

Transformers are installed on top of utility poles, on concrete pads in neighborhood

of residential area and shopping centers, under sidewalks and city streets and in enclosed substations. 
Therefore transformer must have "Fire and Environmental" safe because public safety one of paramount concern. FR3 fluid is an insulating fluid that offers many benefits including increased fire and environmental safety, and enhanced performance and longevity of the transformer [9].

\section{A. A comparison between Mineral Oil Dielectric Coolant and FR3 Dielectric Coolant [9].}

\begin{tabular}{|c|c|}
\hline Mineral Oil Dielectric Coolant & FR3 Dielectric Coolant \\
\hline $\begin{array}{l}\text { - Made from petroleum } \\
\text { - Fire point is } 155{ }^{0} \mathrm{C}\left(311^{0} \mathrm{~F}\right) \\
\text { - Ignitable by electrical arcs, and once ignited, the } \\
\text { fire is typically self-propagating } \\
\text { - Clean-up of most mineral oil spills is required by } \\
\text { regulations } \\
\text { - Extinguishing vault (under street/sidewalk) } \\
\text { transformer fires may involve flooding the } \\
\text { underground vault with water, producing } \\
\text { hundreds or thousands of gallons of } \\
\text { contaminated water }\end{array}$ & $\begin{array}{l}\text { - Produced from a renewable source: domestically } \\
\text { grown soybeans } \\
\text { - Fire point is } 360{ }^{0} \mathrm{C}\left(680{ }^{\circ} \mathrm{F}\right) \\
\text { - The high fire point essentially eliminates both } \\
\text { ignition from arcing and sustained burning } \\
\text { - Rapid and complete biodegradation per EPA test } \\
\text { method } \\
\text { - Non-toxic under oral and aquatic testing regimens } \\
\text { - Proven to increase the life of a transformer's } \\
\text { paper insulation material by decades, increasing } \\
\text { the transformer asset's life }\end{array}$ \\
\hline
\end{tabular}

\section{DESIGN PROCEDURE}

Transformers on operating experience and the developments in the power systems abroad, certain revisions in the specifications can be considered for achieving higher dependability (reliability and availability) with cost advantages [10]. It is proposed to reduce the size and weight of the transformer i.e. core size and copper volume by marginally increasing the values of flux density and current density, at the same time there would not be much effect on the efficiency and temperature rise [3].

\section{B. Effect of Flux Density and Current Density on Distribution Transformer}

\section{1) Effect of higher flux density}

When flux density is slightly increased the area of crosssection of the core is reduced and iron weight as well as transformer weight is reduced. As the core cross- sectional area is reduced the mean turn length of high voltage and lowvoltage windings is also reduced as well as copper weight and copper losses are reduced. On the other hand iron losses i.e. eddy current and hysteretic losses are increased, efficiency marginally reduced and temperature rise increases slightly, saturation occurs and so magnetizing current is slightly increased with the result power factor become slightly poor.

\section{2) Effect of higher current density}

When the current density is increased the windings crosssectional area is reduced and hence the volume and copperweight is reduced. Copper losses are increased slightly. Efficiency is reduced and temperature rise increases.
The load is not constant and is varying from No-load to Full-load in a distribution transformer, accordingly copper-losses are varying. Even with increase in current density, at low load the copper- losses will be low and would not much affect the efficiency and temperature rise.

3) Case Study

In analysis and design of distribution transformer a question arises which set of flux density and current density is most suitable for optimization of distribution transformer for a maximum all day efficiency.

In this connection the present work demonstrates that the effect of flux density and current density on optimization of distribution transformer. In order to study the effect of flux density and current density, three tables are compared. Each table has a particular current density value and different set of flux density value.

The Analysis and design of 315 KVA distribution trans former 33/.433 KV, Delta/ Star have been done and obtain following results the value of Current Density is 2.9, 3.0, 3.2 $\mathrm{amp} / \mathrm{sq}$. mm respectively.

\section{RESUlTS AND DisCUSSION}

Generally in design of distribution transformers (up to a size of about 500kvA, used to step down the distribution voltage to a standard service voltage) are used the value of flux density between 1.65 to $1.7 \mathrm{~Wb} / \mathrm{m}^{2}$ and value of current density between 2.9 to $3.0 \mathrm{amp} / \mathrm{mm}^{2}$. In this paper, the proposed current and flux density of distribution transformer are $1.75 \mathrm{~Wb} / \mathrm{m}^{2}$ and $3.2 \mathrm{amp} / \mathrm{mm}^{2}$ respectively, which is most suitable for optimization of distribution transformer. 
TABLE 1: 315KVA, 33/0. $433 \mathrm{KV}$ AT CURRENT DENSITY = 2.9 AMP/SQ MM

\begin{tabular}{|l|l|l|l|}
\hline Flux density (Wb/Sq m) & 1.65 & 1.70 & 1.75 \\
\hline Core weight (Kg) & 600 & 589 & 574 \\
\hline Core cost (Rs) & 126000 & 123690 & 120540 \\
\hline CU-wt.(k.g.) & 316 & 306 & 294 \\
\hline Cu-cost (Rs.) & 123240 & 119340 & 114660 \\
\hline Total cost (Rs) & 249240 & 243030 & 235200 \\
\hline Core loss (KW) & 1.0 & 1.05 & 1.15 \\
\hline Cu-loss (KW) & 3.66 & 3.59 & 3.57 \\
\hline Total Loss(KW) & 4.66 & 4.64 & 4.72 \\
\hline Impedance (in \%) & 4 & 4 & 4 \\
\hline $\begin{array}{l}\text { Efficiency (0.8 p.f.) } \\
\text { All day Efficiency (These are } \\
\text { based on load cycle ) }\end{array}$ & $98.33 \%$ & $98.192 \%$ & $98.161 \%$ \\
\hline
\end{tabular}

${ }^{*}$ Rs represent Indian currency Rupees

TABLE 2: 315KVA, 33/0. 433 KV AT CURRENT DENSITY= 3 AMP/ SQ MM

\begin{tabular}{|l|l|l|l|}
\hline Flux density (Wb/Sq m) & 1.65 & 1.70 & 1.75 \\
\hline Core weight (Kg) & 599 & 588 & 574 \\
\hline Core cost (Rs) ${ }^{*}$ & 125790 & 123480 & 120540 \\
\hline CU-wt.(k.g.) & 310 & 302 & 294 \\
\hline Cu-cost (Rs.) & 120900 & 117780 & 114660 \\
\hline Total cost (Rs) & 246690 & 241260 & 235200 \\
\hline Core loss (KW) & 1.0 & 1.05 & 1.15 \\
\hline Cu-loss (KW) & 3.73 & 3.66 & 3.57 \\
\hline Total Loss(KW) & 4.73 & 4.71 & 4.72 \\
\hline Impedance (in \%) & 4 & 4 & 4 \\
\hline Efficiency (0.8 p.f.) & $98.158 \%$ & $98.165 \%$ & $98.161 \%$ \\
\hline $\begin{array}{l}\text { All day Efficiency (These are } \\
\text { based on load cycle ) }\end{array}$ & $98.305 \%$ & $98.28 \%$ & $98.26 \%$ \\
\hline
\end{tabular}

TABLE 3: 315KVA, 33/0. 433 KV AT CURRENT DENSITY=3.2 AMP/ SQ MM

\begin{tabular}{|l|l|l|l|}
\hline Flux density (Wb/Sq m) & 1.65 & 1.70 & 1.75 \\
\hline Core weight (Kg) & 598 & 587 & 573 \\
\hline Core cost (Rs) & (125580 & 123270 & 120330 \\
\hline CU-wt.(k.g.) & 305 & 296 & 290 \\
\hline Cu-cost (Rs.) & 118950 & 115440 & 113100 \\
\hline Total cost (Rs) & 244530 & 238710 & 233430 \\
\hline Core loss (KW) & 1.0 & 1.05 & 1.15 \\
\hline Cu-loss (KW) & 3.81 & 3.74 & 3.64 \\
\hline Total Loss(KW) & 4.81 & 4.79 & 4.79 \\
\hline Impedance (in \%) & 4 & 4 & 4 \\
\hline
\end{tabular}




\begin{tabular}{|l|l|l|l|}
\hline Efficiency (0.8 p.f.) & $98.108 \%$ & $98.127 \%$ & $98.135 \%$ \\
\hline $\begin{array}{l}\text { All day Efficiency (These are } \\
\text { based on load cycle ) }\end{array}$ & $98.3 \%$ & $98.28 \%$ & $98.26 \%$ \\
\hline
\end{tabular}

TABLE-4 ALL DAY EFFICIENCIES ARE CALCULATED UNDER THE FOLLOWING LOAD CYCLE IN SUMMER SESSION

\begin{tabular}{|c|c|c|}
\hline Time Duration & Power factor & Load (KW) \\
\hline 00 a.m. to 01 a.m. & 0.80 & 168.00 \\
\hline 01 a.m. to 02 a.m. & 0.80 & 168.00 \\
\hline 02 a.m. to 03 a.m. & 0.80 & 184.40 \\
\hline 03 a.m. to 04 a.m. & 0.80 & 201.60 \\
\hline 04 a.m. to 05 a.m. & 0.80 & 201.60 \\
\hline 05 a.m. to 06 a.m. & 0.80 & 201.60 \\
\hline 06 a.m. to 07 a.m. & 0.70 & 220.50 \\
\hline 07 a.m. to 08 a.m. & 0.70 & 220.50 \\
\hline 08 a.m. to 09 a.m. & 0.70 & 220.50 \\
\hline 09 a.m. to 10 a.m. & 0.75 & 220.50 \\
\hline 10 a.m. to 11 a.m. & 0.75 & 189.00 \\
\hline 11 a.m. to 12 noon & 0.75 & 141.75 \\
\hline 12 noon to 01 p.m. & 0.75 & 141.75 \\
\hline 01 p.m. to 02 p.m. & 0.75 & 157.50 \\
\hline 02 p.m. to 03 p.m. & 0.75 & 173.25 \\
\hline 03 p.m. to 04 p.m. & 0.75 & 189.00 \\
\hline 04 p.m. to 05 p.m. & 0.75 & 195.30 \\
\hline 05 p.m. to 06 p.m. & 0.75 & 204.75 \\
\hline 06 p.m. to 07 p.m. & 0.90 & 264.60 \\
\hline 07 p.m. to 08 p.m. & 0.95 & 287.28 \\
\hline 08 p.m. to 09 p.m. & 0.95 & 299.25 \\
\hline 09 p.m. to 10 p.m. & 0.90 & 264.60 \\
\hline 10 p.m. to 11 p.m. & 0.90 & 226.80 \\
\hline 11 p.m. to 12 midnight & 0.90 & 207.90 \\
\hline
\end{tabular}

\section{A.Case-I}

A transformer of flux density $1.65 \mathrm{~Wb} / \mathrm{m}^{2}$ in Table- 1 is compared with a transformer of flux density $1.75 \mathrm{~Wb} / \mathrm{m}^{2}$ in Table- 3 , it is observed that the proposed transformer saves $4.5 \%$ core and $8.2 \%$ copper which reduces transformer cost by Rs. 15810 . On other hand all day efficiency of proposed transformer reduces by $0.07 \%$ (from Table- 4 ).

\section{Case-II}

A transformer of flux density $1.7 \mathrm{~Wb} / \mathrm{m}^{2}$ in Table- 1 is compared with a transformer of flux density $1.75 \mathrm{~Wb} / \mathrm{m}^{2}$ in Table-3, it is observed that the proposed transformer saves $2.72 \%$ core and $1.36 \%$ copper which reduces transformer cost by Rs. 9600. On other hand all day efficiency of proposed transformer reduces by $0.07 \%$ (from Table-4).

\section{Case-III}

A transformer of flux density $1.65 \mathrm{~Wb} / \mathrm{m}^{2}$ in Table- 2 is compared with a transformer of flux density $1.75 \mathrm{~Wb} / \mathrm{m}^{2}$ in Table- 3 , it is observed that the proposed transformer saves $4.34 \%$ core and $6.45 \%$ copper which reduces transformer cost by Rs. 13260. On other hand all day efficiency of proposed transformer reduces by $0.045 \%$ (from Table-4).

\section{E. Case-IV}

A transformer of flux density $1.7 \mathrm{~Wb} / \mathrm{m}^{2}$ in Table-2 is compared with a transformer of flux density $1.75 \mathrm{~Wb} / \mathrm{m}^{2}$ in Table-3, it is observed that the proposed transformer saves $2.55 \%$ core and $3.97 \%$ copper which reduces transformer cost by Rs. 7830. On other hand all day efficiency of proposed transformer reduces by $0.02 \%$ (from Table-4). 


\section{CONCLUSION}

This paper presents a cost -effective, reliable and environmental friendly distribution transformer.

The cost-effective design of distribution transformer, contributes to meet demand of electricity within budget as well as it is reliable and environmental friendly. Such characteristics are also necessary because the global warming is increasing with the increasing atmospheric levels of carbon dioxide (co2). As the global community is to used on mitigating the effect of global warming by reducing green house gases. This will achieve when FR3 oil is used in transformer in place of mineral oil. FR3 oil extends the life of transformer. Its fire and flash point more then twice that of mineral oil.It can cut fire-safeguarding cost for substations by hundreds of thousands of dollars. So use of FR3 oil in transformer makes it reliable and environmentally friendly.

On the other hand regarding cost-effectiveness a design of 315KVA 33KV/420V, Delta/ Star, distribution transformer with different flux densities and current densities are considered. Common practice is to design such transformer with flux densities of 1.65 to $1.7 \mathrm{~Wb} / \mathrm{m}^{2}$ and current densities 2.9 to $3.0 \mathrm{amp} / \mathrm{mm}^{2}$. It is examined that if design is carried out with flux density of $1.75 \mathrm{~Wb} / \mathrm{m}^{2}$ and current density of $3.2 \mathrm{amp} / \mathrm{mm}^{2}$, then is considerable saving in the weight and cost of core material and copper. There is marginal decrease in all day efficiency of the transformer. It is felt optimum size and cost of the distribution transformer in the range of around 300 to $350 \mathrm{KVA}$ Can be achieved by designing the distribution transformer with flux density $1.75 \mathrm{~Wb} / \mathrm{m}^{2}$ and current density $3.2 \mathrm{amp} / \mathrm{mm}^{2}$ with the reduction in weight and size of the transformer it will be easier to install the transformer.

\section{REFERENCES}

[1] Karstein Longva-"Natural ester distribution transformer improved reliability and environmental safety", Nordic insulation symposium-Nord-IS 05- Trondheim, Norway, June 13-15, 2005, pp. 293-295

[2] Mohammed Y.Abu- Sada, Zakariya Al-Hamouz, " Cost effective of distribution transformer using a Nonlinear Programming Algorithm optimization "IEEE Conference on grid and cooperative computing 2004, pp.294-298.

[3] S. Corbodzic - "A new approach to Assessment and utilization of distribution power Transformer"- Phd Thesis, School of Engineering, Victoria University, Melbourne, Australia, pp-2 (April 2006)

[4] A report on "Transformer Industry set for a high voltage growth" (May 2008) (www.commodityonline.com)

[5] Anonymous, "Envirotemp FR3 fluid", Bulletin 00092 product information June, 2001 (www.cooperpower.com) pp. 1-8

[6] Anonymous, "FR3 Strive for a fire-free future", Feb 2004 (www.cooperpower.com)

[7] Anonymous, A report on "FR3 fluid provides sustainable alternative for reducing carbon footprint", 2008.

[8] Anonymous, "A report on Energy for generations", perennial news, volume IX number 2, perennial public power district, york, Nebraska, April 2008

[9] Anonymous, " Envirotemp FR3 Dielectric Coolant Fact Sheet", 2006, (www.cooperpower.com)

[10] A Agarwal, "400kv transformer specifications in India-proposals for economy and dependability". International Conference on large power Transformers-Modern Trends in Application, Installation, Operation \& Maintenance, (12-13 October 2006), New Delhi, India.

Er. Manish Kumar Srivastava is working as senior assistant Professor in Department of Electrical Engineering, college of engineering and

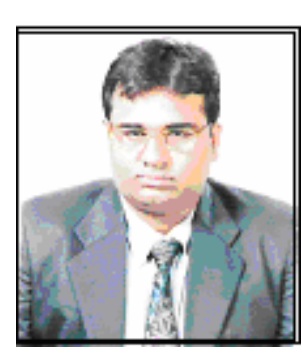

technology; Allahabad Agricultural Institute-Deemed University, Allahabad U.P (India). He has several years of teaching experience in the field of electrical engineering. $\mathrm{He}$ is a nodal officer in university publication division and also served as proctor in university. $\mathrm{He}$ has bachelor degree in electrical engineering. M.Tech. Degree in "control \& instrumentation". He has also obtained M.B.A. degree. He has presented several national and international technical papers and participated in various seminars and conferences. He has published his research papers in international and national Journal. He has written a book entitled "Instrumentation and Process Control". He has selected for "Shiksha Rattan Puraskar" and "Certificate of Excellence" 